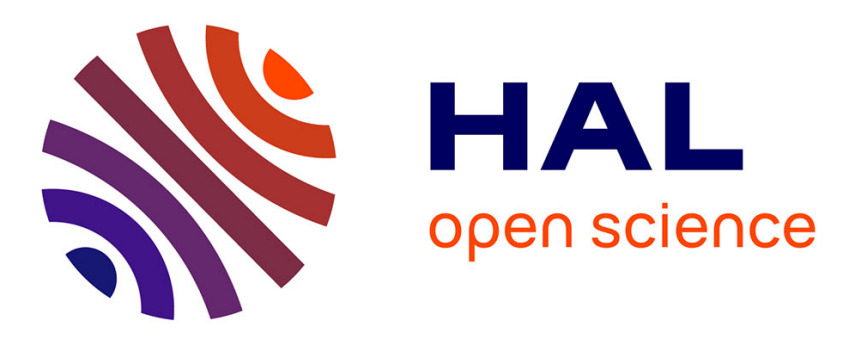

\title{
Interference between active implanted medical devices and electromagnetic field emitting devices is rare but real: results of an incidence study in a population of physicians in France
}

Martine Hours, Inès Khati, Joël Hamelin

\section{To cite this version:}

Martine Hours, Inès Khati, Joël Hamelin. Interference between active implanted medical devices and electromagnetic field emitting devices is rare but real: results of an incidence study in a population of physicians in France. PACE - Pacing and Clinical Electrophysiology, 2014, 37 (3), pp. 290-296. 10.1111/pace.12269 . hal-00927026

\section{HAL Id: hal-00927026 \\ https://hal.science/hal-00927026}

Submitted on 20 Mar 2019

HAL is a multi-disciplinary open access archive for the deposit and dissemination of scientific research documents, whether they are published or not. The documents may come from teaching and research institutions in France or abroad, or from public or private research centers.
L'archive ouverte pluridisciplinaire HAL, est destinée au dépôt et à la diffusion de documents scientifiques de niveau recherche, publiés ou non, émanant des établissements d'enseignement et de recherche français ou étrangers, des laboratoires publics ou privés. 
HOURS, Martine ; KHATI, Inès ; HAMELIN, Joël, 2014, Interference between active implanted medical devices and electromagnetic field emitting devices is rare but real: results of an incidence study in a population of physicians in France, Pacing and clinical electrophysiology, WILEY, 19 p, DOI:10.1111/pace.12269

Interference between active implanted medical devices and electromagnetic field emitting devices is rare but real: results of an incidence study in a population of physicians in France

Martine Hours MD, $\mathrm{PhD}^{\mathrm{a}, \mathrm{b}}$, Inès Khati $\mathrm{MSc}^{\mathrm{a}, \mathrm{b}}$, Joel Hamelin $\mathrm{PhD}^{\mathrm{c}}$

a_Lyon University, F-69622, Lyon, France ;

Lyon-1 University, UMRESTTE, F-69373 Lyon, France;

${ }^{\mathrm{b}}$ IFSTTAR, UMRESTTE, F-69675 Bron, France.

${ }^{\mathrm{C}}$ Center for Strategic Analysis, 18 rue de Martignac, 75700 Paris, France

Short Title: implantable medical devices and EMF emitting sources

\section{Acknowledgments}

The authors thank the Santé et Radiofréquences Foundation, which triggered the study during its Scientific Council's discussions, and Françoise Boudin in particular; Marjolaine Hours for setting up and executing the postal survey; Olivier Merckel (ANSES) for his support, and all the physicians who agreed to take part.

Special thanks to lain McGill for comments and manuscript editing.

Funding: We acknowledge funding from the French Agency for Food, Environmental and Occupational Health and Safety (ANSES: convention $\mathrm{N}^{\circ}$ 2009-CRD-39; report on 2011), for data collection and analysis.

The authors have no conflict of interest to declare.

\section{Corresponding author}

Martine HOURS

Epidemiological Research and Surveillance Unit in Transport Occupation and Environment (UMRESTTE)

Faculty of medicine, Domaine Rockefeller

8 avenue Rockefeller

69373, LYON Cedex 08, France

Tel.: 33472142522

Fax: 33472376837

martine.hours@ifsttar.fr 


\section{Abstract}

Background and objective: Assessing the behavior of active implanted medical devices in response to electromagnetic field (EMF) transmitters is a current issue of great importance. Given the multiplication telecommunication systems and our lack of knowledge as to the impact of electromagnetic effects, the present study investigated the reality of possible AIMD disturbance by electromagnetic fields by questioning health professionals.

Method: A self-administered postal questionnaire was sent to almost 5,000 physicians in 5 specialties: cardiology, endocrinology, ENT, urology and neurology. It collected data on the existence and annual number of incidents observed and the conditions under which they occurred, the EMF sources involved, and the means of managing the malfunctions.

Results: 1,188 physicians agreed to participate. $16 \%$ reported cases of implant failure, three-quarters of whom, mainly in cardiology, reported rates of at least 1 incident per year - amounting to more than 100 incidents per year in all. Severity appeared to be moderate (discomfort or transient symptoms), but frequently required resetting or, more rarely, replacing the device. Some serious incidents were, however, reported.

The sources implicated were basically of 2 types: electronic security systems (antitheft and airport gates) and medical electromagnetic radiation devices.

These incidents were poorly reported within the public health system, preventing follow-up and effective performance of alert and surveillance functions.

Conclusion: Although minor, the risk of interference between EMF sources and AIMDs is real and calls for vigilance. It particularly concerns antitheft and airport security gates, although other sources may also cause incidents.

Key Words: Active implanted medical devices, Medical survey, Adverse effects, Electromagnetic fields, Electromagnetic interference, Equipment failure, Postal questionnaire, Security systems, mobile phones . 


\section{Introduction}

We live in an environment where are increasing sources of electromagnetic fields (EMF) to which active implanted medical device (AIMD) bearers are exposed on a day-to-day basis. For frequencies in the $80 \mathrm{MHz}$ to $1 \mathrm{GHz}$ range, current regulations require all electrical devices not covered by dedicated standards to function in an environment with an EMF not exceeding 3 volts per meter. This safety level is, however, often raised for equipment considered to be critical: thus for medical life-support devices the immunity level is raised to $10 \mathrm{~V} / \mathrm{m}$ between 0.8 and $2.5 \mathrm{GHz}$.

There have been 3 distinct types of study of EMF interference with AIMDs: in-vivo studies reproducing a real-life situation, in-vitro studies of AIMD immunity by simulation of the EMF conditions to which AIMDs are subject, and finally clinical studies. Of these, only the in-vitro studies using a phantom equivalent of biological tissue allow cross-study comparison of results.

The considerable increase in the use of radio frequencies in everyday life is increasingly exposing AIMD (pacemaker, internal neurostimulator, insulin pump, etc.) bearers to EMFs exceeding $3 \mathrm{~V} / \mathrm{m}$. The ubiquity of EMFs precludes avoidance of at-risk situations: a single exposure may be enough to disturb AIMD functioning, with harmful physiological impact on the bearer. There have been more and more studies over a number of years seeking to assess and describe such EMFrelated risks ${ }^{1}$, mainly in cardiological (pacemakers and implantable automatic defibrillators (IAD)) and ENT (cochlear implants), which are the most widely used.

Situations in which the $3 \mathrm{~V} / \mathrm{m}$ (not to mention $10 \mathrm{~V} / \mathrm{m}$ ) threshold is exceeded are rare but probable: e.g., security or antitheft gates or radiofrequency identification (RFID) readers, in presence of radio-telephones, particularly in confined spaces such as subways or elevators, or high-power transmitters; in medical practice, high exposure may also be involved in magnetic resonance imaging (MRI) or the use of an electric knife. It is technically possible that such exposure disturbs AIMDs, causing malfunction and thus transient or more serious problems for the bearer: burns, impact on brain tissue in contact with a neurostimulation electrode, uncontrolled discharge of insulin or other drugs, pacemaker crash, etc. ${ }^{2}$. 
Although bearers are usually warned of such situations by their physicians and advised to make themselves known in them, it is not easy to be aware of all the possible sources of exposure they may encounter on a day to day basis so as to be able to avoid them. For this reason and given the increasing number of AIMD bearers, EMF-related disturbance is a current issue.

Individuals and associations have on several occasions expressed their worries to the French public authorities about incidents experienced by AIMD bearers exposed to radiofrequency fields, but the issue has not been reported to have been taken up by the health authorities and no real action has been taken, current regulations being considered sufficient for prevention purposes.

A certain number of cases having, however, come to our knowledge, we felt it necessary to investigate the reality of such incidents as testified to by physicians and assess the seriousness of the situation in terms of frequency, severity and circumstances so as to be able to provide the health authorities with precise data.

\section{Methods}

Study population: The study population comprised physicians dealing with AIMD bearers in 5 specialties: cardiology, endocrinology, neurology and neurosurgery, ENT and urology.

Data: A questionnaire, brief enough to be quickly completed, comprised 3 main rubrics:

- Preliminary: physician identification and medical activity (number of AIMDs and bearers followed) and complaints of AIMD failure associated with electrical interference during the year;

- Description of the complaint: type of AIMD, number of incidents per year, type of physiological or symptomatic disturbance, type of EMF source implicated, type of corrective action required, description of situation;

- Reporting of incidents.

Survey methodology (Two-step survey): 
The first step comprised a postal self-administered questionnaire. Respondents were selected at random from a national database, from an estimated 18,000 relevant physicians. With an expected incident report rate of $3 \%$ and to obtain a data set for about 150 physicians reporting 1 to 3 incidents per physician per year, 5,000 physicians were contacted.

Having failed to obtain lists of physicians from the National Medical Order, we used a database derived from the Yellow Pages of the Phone Book. Randomization took account of population per specialty. To obtain a sufficient number of responses per specialty, questionnaires were sent to all listed endocrinologists $(n=856)$, neurologists $(n=616)$ and urologists $(n=381)$, the numbers of which were relatively small, and to $25 \%$ of the cardiologists $(n=1,717)$ and $35 \%$ of the ENT specialists ( $n=1,296)$. In all, 4,866 specialists were sent the questionnaire. A reminder was sent after 1 month, to maximize response.

The second step comprised a telephone survey of respondents having reported at least 1 incident, to allow more precise analysis of the incidents reported: precise devices involved, and circumstances of the incident.

Results were reported as frequency tables.

\section{Results}

For 120 physicians, envelopes were returned to sender by the Post as "unknown at this address". 1,188 of the 4,866 physicians contacted replied (response rate: $25 \%$ ). 333 wrote that they were not concerned by the survey as their practice did not involve following AIMD bearers. 137 of the 855 physicians concerned by the survey reported having observed at least 1 incident (figure 1).

\section{Description of incidents}

$16 \%$ of respondents were aware of at least 1 incident resulting from interference between an AIMD and an EMF-emitting device. Proportionally, cardiologists and urologists were the most concerned (Table 1). Most physicians reporting an incident had observed less than 1 incident per year.

Pacemakers were the implants most frequently $(>50 \%)$ concerned (Table 2$)$. 
Most incidents involved malfunction, resulting, for example, in abnormal stimulation (Table 3). Devices frequently went into fail-safe mode after the initial failure; in $12 \%$ of cases, there was total shut-down. Complete resetting was especially required for cardiological devices: for $70 \%$ of pacemakers and $56 \%$ of defibrillators.

Patient disturbance ranged from simple discomfort ( $40 \%$ of cases) to transient symptoms (39\%); in $18 \%$ of cases, symptoms were serious enough to require emergency treatment. The kind of disturbance depended on the type of AIMD: insulin pumps, valves and neurostimulators gave rise to the most severe symptoms.

\section{EMF devices implicated}

The EMF sources most frequently implicated were store antitheft gates $(21 \%)$, followed by electrosurgical knives $(13 \%$, despite real improvements that have been made and increasing physician awareness of and adherence to instructions for use) and airport security gates (10\%) (Table 4). Cell-phones and Wi-Fi stations were involved in less than $10 \%$ of cases, and Digital Enhanced Cordless Telephone (DECT) base stations and microcells were very seldom implicated.

It was noteworthy that 8 of the 11 cochlear implant incidents involved telecommunication radiofrequency sources: 1 DECT handset, 2 DECT bases, 2 cell-phones, 1 microcell in a store, $1 \mathrm{Wi}$-Fi base, and 1 radio transmitter at very close proximity.

Half of the physicians concerned by the survey reported AIMD failure to at least 1 organization, mainly (77\%) the manufacturer. French Health authorities (health product safety agency (AFSSAPS) or Ministry of Health, France) were contacted in only 2 out of 170 cases; the Order of Medicine was never contacted. The other 33 reports were made to the implanting physician. 


\section{Discussion}

The frequency of AIMD incidents associated with EMFs was low (involving only $16 \%$ of physicians potentially concerned), but non-zero. Cardiologists and urologists were the specialists mainly involved. Severity was relatively low: three-quarters of incidents induced only transient physiological and/or symptomatic disturbance, with minor impact (discomfort or transient symptoms). However, $18 \%$ of incidents required treatment; incidents involving insulin pumps, valves and neurostimulators induced the most severe symptoms.

EMF sources were basically of 2 types: electronic security systems (store antitheft gates and airport security gates) and medical electromagnetic radiation devices (electric knives, radiation therapy, MRI scanners), although the incident-rates associated with the latter have decreased. Security equipment has been the focus of a few previous reports. Gimbel et $\mathrm{al}^{2}$ reported 2 cases of failure ( 1 IAD and 1 pacemaker) induced by store security apparatus: the IAD bearer received 2 inappropriate shocks in 30 seconds just after passing through the gate, and the pacemaker bearer lost consciousness while in the gate until he was finally removed. Other studies ${ }^{3,4}$ showed that security system frequencies are sometimes close to cardiac device signals, and thus liable to induce failure. In contrast, in a largescale in-vivo study in $2003^{5}, 200$ pacemaker and 148 IAD bearers were asked to cross an airport security gate at varying angles; continuous ECG recording assessed any change in stimulation. Results suggested that the apparatuses were harmless, with no cases of interference, heart problems or implant failure. The present findings contradict these results for a single security gate tested on an experimental protocol rather than in real-life situations which only an epidemiological study can assess.

A very large number of medical and surgical electromagnetic radiation devices are liable to disturb AIMD functioning. The potential risks associated with electric knives have been widely discussed ${ }^{6,7}$, and it is now well known that they can adversely affect AIMD bearers; several means of reducing this interference have been suggested $^{8,9}$ : e.g., using the electric knife in bipolar mode. 
The literature on MRI machines is abundant: AIMDs seem to be very vulnerable to this diagnostic tool, which applies an intense magnetic field involving very high frequency emissions. Cochlear implants, for example, are liable to be displaced and their electronic system to be affected ${ }^{10,11}$. The risk with cardiac devices is of inhibition or on the contrary of excessive stimulation during MRI examination ${ }^{12,13}$. With neurostimulators, there is a proven risk of implant heating and dysfunction ${ }^{14}$. When AIMD bearers require radiation therapy, the risk of interference also appears to be serious. In 2006, Uiterwaal ${ }^{15}$ sought to determine the effect and associated risk of radiation therapy on IADs, and found systematic interference in all 11 devices subjected to ionizing radiation.

The initial controversy concerned mobile communication, given its soaring use. We found 8 incidents involving telephones, 5 involving $\mathrm{Wi}-\mathrm{Fi}$ and 4 involving microcells: although few, they demonstrate that a risk exists and will cause more incidents as the sources multiply and grow closer together. Several studies in recent years have analyzed interactions between AIMDs and new communication technologies. Tandogan ${ }^{16}$ tested 43 IAD bearers, and found no impact of testing on IAD functioning. Jimenez ${ }^{17}$ surveyed 72 IAD bearers on adverse effects due to cell-phones, and found no clinically perceptible interference. In contrast, a multicenter study ${ }^{18}$ assessed analogic and digital phone impact on 980 pacemaker bearers: a series of tests revealed clinically significant effects in $6.6 \%$ of cases. Another study ${ }^{19}$ focused on cell-phone effects inside hospitals, where the need for restrictions is being questioned, and found that, although the incident rate has been reduced by improved electromagnetic compatibility in AIMDs, cases remain in which cell-phones impact medical equipment. Likewise, given the spread of portable music readers, recent studies have examined their impact on AIMDs and on cardiological implants in particular. In vitro ${ }^{20}$ and in vivo studies ${ }^{21,22}$, covering a wide range of AIMDs, assessed the EMF levels and impact of portable music readers and found no evidence of interference or effect on IAD or pacemaker function. In contrast, Thaker ${ }^{23}$, in 2008, reported several cases of interference: they assessed the impact of EMFs emitted by 4 iPods on more than 100 pacemakers, implementing 2 test phases so as to ensure reproducibility; results pointed to a probable risk of interference between multimedia readers and pacemakers. 
Electronic security systems and medical EMF sources are the most frequent causes of interference, but other sources may also be implicated. The present results notably include 4 cases in industrial settings: welding irons and arc welding; hitherto using such tools was strongly advised against in AIMD bearers but ongoing research is seeking to draw up safety measures to allow AIMD bearers to work without danger in industrial settings ${ }^{24}$. In everyday life, on the other hand, identifying sources of interference is less straightforward, as many are hard to detect: for example, everyday objects such as jewelry or clothing increasingly use strong magnets which, despite their small size, may induce strong static magnetic fields. In vitro studies have determined the threshold of the electromagnetic fields beyond which IAD could be disrupted by a magnet: Ryf et al. ${ }^{25}$, for example, assessed the maximum distance between IADs and magnets commonly used at home or at work at which magnetic malfunction is still observed. Wolber et al. ${ }^{26}$ in a clinical study, placed different magnets of various power on the skin of patients with PM or DAI and found that all patients presented disturbance of the electrical parameters of the heart. Finally, Beinart ${ }^{27}$ reported a case of electromagnetic interference between an IAD and the small magnetic press-studs of a jacket; this incident, similar to a case in the present study involving magnets in a hairdresser's gown, led to complete reprogramming of the implant.

Constantly developing, electromagnetic environments confront society with the question of their public health impact. The present study therefore sought to shed light on the relationship and underlying problems of certain EMF-exposed AIMDs.

The conclusions do not claim to give a precise account of the issue and in particular do not include any annual incident frequency as the survey was based on subjective reports. There were several study limitations: the response rate of $25 \%$ was good for a postal survey but made exact calculation difficult as it was not known whether physicians failed to respond because they had no AIMD bearers in their practice or because they did not wish to respond; this reporting bias likely led to underestimation of the real frequency of electromagnetic incidents. Memory bias in terms of frequency and date of incident doubtless led certain physicians to report some old cases, although 
the study sought to analyze only recent cases thanks to information gleaned during the second telephone interview; and the difficulty for the physician to distinguish radiofrequency and lowfrequency related incidents led to all reported incidents being included for analysis. Furthermore, physicians may not have adequately declared the consequences of compatibility incidents: for example, the total failure rate of $7 \%$ seems to be higher than expected ${ }^{28}$.

In any event, the data collected here seem to us to confirm the reality of these incidents that the health authorities have not been in a position to assess, and to call for real vigilance. The means of monitoring and preventing AIMD failure need to be planned for: one approach could be risk management education by raising awareness and/or instituting mandatory training both for AIMD bearers as a whole and for the health professionals concerned by the issue. Other approaches, put forward by patient associations, include training for airport controllers and information posters concerning EMF values to be posted in such places as hospitals, industrial premises, etc. Finally, the occurrence of such incidents should encourage AIMD makers to develop ever more resistant designs.

\section{Conclusion}

The question of EMF impact on AIMDs is real, as is the associated health risk: several cases of implant failure were linked to low or high frequency electrical devices. The actual number of incidents was, however, small. Some EMF sources emerged as posing more risk than others: security equipment (antitheft and airport security gates) and certain medical devices involving electromagnetic radiation (e.g., electrosurgical knives). By reinforcing AIMD immunity, manufacturers could guard against an increase in the number of incidents. In most cases, incidents were momentary, although they could endanger the safety of certain patients. Reporting to health authorities appeared to be virtually nonexistent; physicians may fail to report failures spontaneously, being faced by a very limited number of cases, of moreover limited severity. 


\section{References}

1. Misiri J, Kusumoto F, Goldschlager N: Electromagnectic interference and implanted cardiacdevices: the non medical environment. Clin Cardiol 2012; 35:276-280.

2. Gimbel JR, Cox JW: Electronic article surveillance systems and interactions with implantable cardiac devices : risk of adverse interactions in public and commercial space. Mayo Clinic proceedings $2007 ; 82: 318-322$.

3. Mathew P, Lewis C, Neglia J, Krol R, Saksena S: Interaction between electronic article surveillance systems and implantable defibrillators: insights from a fourth generation ICD. Pacing Clin Electrophysiol 1997; 20:2857-2589.

4. Groh W, Boschee S, Engelstein E, et al.: Interactions between electronic article surveillance systems and implantable cardioverter-defibrillators. Circulation 1999; 100:387-392.

5. Kolb C, Schmieder S, Lehmann G, et al.: Do airport metal detectors interfere with implantable pacemakers or cardioverter-defibrillators? J Am Coll Cardiol 2003; 41:2054-2059.

6. Colavolpe J, Assouan X, Bonnet M: Anaesthetising a human patient with implanted defibrillator or pacemaker. Anesthésie-Réanimation 2007; B-10:336-401.

7. Di Donato P. Interactions between active implanted medical devices and other medical devices: Agence française de sécurité sanitaire des produits de santé (AFSSAPS); février 2005 2005.

8. American Society of Anesthesiologists Task Force on perioperative management of patients with cardiac rhythm management devices: Practice advisory for the perioperative management of patients with cardiac rhythm management devices: pacemakers and implantable cardioverter-defibrillators. Anesthesiology 2005; 103:186-198.

9. American Society of Anesthesiologists: Practice Advisory for the Perioperative Management of Patients with Cardiac Implantable Electronic Devices: Pacemakers and Implantable Cardioverter-Defibrillators An Updated Report by the American Society of Anesthesiologists 
Task Force on Perioperative Management of Patients with Cardiac Implantable Electronic Devices. Anesthesiology 2011; 114:247-261.

10. Tognola G, Parazzini M, Sibella F, Paglialonga A, Ravazzani P: Electromagnetic interference and cochlear implants. Ann Ist Super Sanita 2007; 43:241-247.

11. Deneuve S, Loundon N, Leboulanger N, Rouillon I, Garabedian EN: Cochlear implant magnet displacement during magnetic resonance imaging. Otology \& neurotology 2008; 29:789-790.

12. Frank R, Hidden-Lucet F, Himbert C, Petitot JC, Fontaine G: Cardiac Pacemakers, implantable defibrillators and IRM. Arch Mal Coeur Vaiss 2003; 96:46-49.

13. Anfinsen O-G, Berntsen RF, Aass H, Kongsgaard E, Amlie JP: Implantable cardioverter defibrillator dysfunction during and after magnetic resonance imaging. Pacing Clin Electrophysiol 2002; 25:1400-1402.

14. Sharan A, Rezai AR, Nyenhuis JA, et al.: MR safety in patients with implanted deep brain stimulation systems (DBS). Acta Neurochir Suppl 2003; 87:141-145.

15. Uiterwaal G, Springorum B, Scheepers E, et al: Interference detection in implantable defibrillators induced by therapeutic radiation therapy. Neth Heart J 2006; 14:330-334.

16. Tandogan I, Ozin B, Bozbas $\mathrm{H}$, et al.: Effects of mobile telephones on the function of implantable cardioverter defibrillators. Ann Noninvasive Electrocardiol 2005; 10:409-413.

17. Jimenez A, Hernández Madrid A, Pascual J, et al.: [Electromagnetic interference between automatic defibrillators and digital and analog cellular telephones] Interferencias electromagnéticas entre los desfibriladores automáticos y los teléfonos móviles digitales y analógicos. Rev Esp Cardiol 1998; 51:375-382.

18. Wilke A, Kruse T, Hesse H, Funck R, Maisch B: Interactions between pacemakers and security systems. Pacing Clin Electrophysiol 1998; 21:1784-1788.

19. Anonymous: Cell phones and electromagnetic interference revisited. Health Devices 2006; $35: 449-456$ 
20. Bassen $\mathrm{H}$ : Low frequency magnetic emissions and resulting induced voltages in a pacemaker by iPod portable music players. Biomedical Engineering Online 2008; 7.

21. Webster $G$, Jordao $L$, Martuscello $M$, et al.: Digital music players cause interference with interrogation telemetry for pacemakers and implantable cardioverter-defibrillators without affecting device function. Heart Rhythm 2008; 5:545-550.

22. Chiu CC, Huh J, De Souza L, et al.: A prospective pediatric clinical trial of digital music players: do they interfere with pacemakers ? J Cardiovasc Electrophysiol 2008; 20:44-49.

23. Thaker JP, Patel MB, Shah AJ, et al.: Do Media Players Cause Interference with Pacemakers? Clin Cardiol 2009; 32:653-657.

24. Gurevitz O, Fogel $R$, Herner $M$, et al.: Patients with an ICD can safely resume work in industrial facilities following simple screening for electromagnetic interference. Pacing Clin Electrophysiol 2003; 26:1675-1678.

25. Ryf S, Wolber T, Duru F, et al.: Interference of neodynium magnets with cardiac pacemakers and implantable cardioverter-defibrillators: an in vitro study. Technology and Health Care 2008; 16:13-18.

26. Wolber $T$, Ryf $S$, Binggeli $C$, et al.: Potential interference of small neodynium magnets with cardiac pacemakers and implantable cardioverter-defibrillators. Heart Rhythm 2007; 4:1-4.

27. Beinart R, Guy M, Ellinor P: Intermittent, erratic behaviour of an implantable cardioverter defibrillator secondary to a hidden magnetic source of interference. Eurospace 2011; 13:1508-1509.

28. Poole JE, Gleva MJ, Mela T, et al.: Complication Rates Associated With Pacemaker or Implantable Cardioverter-Defibrillator Generator Replacements and Upgrade Procedures. Results From the REPLACE Registry. Circulation 2010; 122:1553-1561 
Table 1: Distribution of the 137 physicians reporting incidents (out of 855 respondents) according to number of incidents per year

\begin{tabular}{lrrrrrr}
\hline $\begin{array}{l}\text { Number of incidents } \\
\text { per year }\end{array}$ & Cardiology & Endocrinology & Neurology & ENT & Urology & Total \\
\hline & $\mathrm{n}$ & $\mathrm{n}$ & $\mathrm{n}$ & $\mathrm{n}$ & $\mathrm{n}$ & $\mathrm{n}$ \\
\cline { 2 - 3 } & 75 & 13 & 7 & 7 & 6 & 108 \\
$\mathbf{1}$ & 10 & 0 & 0 & 2 & 3 & 15 \\
$\mathbf{2}-\mathbf{3}$ & 7 & 0 & 2 & 2 & 0 & 11 \\
$>\mathbf{3}$ & 2 & 0 & 0 & 0 & 1 & 3 \\
Number of respondents & 410 & 141 & 88 & 185 & 31 & 855 \\
\hline Total & $94(23 \%)$ & $13(9 \%)$ & $9(10 \%)$ & $11(6 \%)$ & $10(32 \%)$ & $137(16 \%)$
\end{tabular}


Table 2: Distribution of incidents by type of implant

\begin{tabular}{ccr}
\hline & \multicolumn{2}{c}{ Number of incidents $^{*}$} \\
\hline Cardiological implant & $\mathrm{n}$ & $\%$ \\
Pacemaker & 90 & 58.1 \\
Defibrillator & 16 & 10.3
\end{tabular}

Neurological implant

$\begin{array}{lcc}\text { Valve } & 6 & 3.9 \\ \text { Stimulator } & 9 & 5.8\end{array}$

Urological implant

Stimulator

$\begin{array}{lll}\text { vesical/Modulator } & 11 & 7.1\end{array}$

ENT implant

$\begin{array}{lll}\text { Cochlear implant } & 11 & 7.1\end{array}$

Endocrinological implant

$\begin{array}{lll}\text { Insulin pump } & 12 & 7.7\end{array}$

$\begin{array}{lll}\text { Total } & 155 & 100\end{array}$

for a given implant, several types of incident are possible 
Table 3: Types of incident by type of implant

\begin{tabular}{|c|c|c|c|c|c|c|c|c|c|}
\hline & \multicolumn{2}{|c|}{ Failure } & \multicolumn{2}{|c|}{ Shut-down } & \multicolumn{2}{|c|}{$\begin{array}{c}\text { Temporary } \\
\text { stoppage with } \\
\text { normal start-up }\end{array}$} & \multicolumn{2}{|c|}{$\begin{array}{l}\text { Other and } \\
\qquad \mathbf{N R}^{*}\end{array}$} & \multirow{2}{*}{$\begin{array}{c}\text { Total } \\
\\
\mathbf{n}\end{array}$} \\
\hline & $\mathbf{n}$ & $\%$ & $\mathbf{n}$ & $\%$ & $\mathrm{n}$ & $\%$ & $\mathbf{n}$ & $\%$ & \\
\hline Pacemaker & 74 & 76.3 & 7 & 7.2 & 9 & 9.3 & 7 & 7.2 & 97 \\
\hline Defibrillator (IAD) & 13 & 68.4 & 0 & - & 5 & 26.3 & 1 & - & 19 \\
\hline Valve & 4 & - & 0 & - & 1 & - & 1 & - & 6 \\
\hline Stimulate & 3 & - & 3 & - & 2 & - & 1 & - & 9 \\
\hline $\begin{array}{l}\text { Vesicle } \\
\text { stimulator/modulator }\end{array}$ & 5 & 38.5 & 4 & - & 3 & - & 1 & - & 13 \\
\hline Cochlear implant & 8 & 61.5 & 3 & - & 2 & - & 0 & - & 13 \\
\hline Insulin pump & 4 & - & 4 & - & 1 & - & 1 & - & 13 \\
\hline Total & 111 & 65.3 & 21 & 12.4 & 23 & 13.5 & 18 & 10.6 & 170 \\
\hline
\end{tabular}

NR: non-response

Percentages calculated only for $n \geq 5$ 
Table 4: Type and frequency of implication of devices underlying AIMD failure

\begin{tabular}{l}
\hline \\
\cline { 2 - 3 }
\end{tabular}

Low frequency devices

Household equipment

5

Other $^{+}$

17

High (including radio-) frequency equipment

Diathermal device

3

Electrosurgical knives

28

13.1

DECT at home/hospital or near base

9

Cell-phone. Ipod

8

Wi-Fi (computer or PDA/router/network access

point or box)

5

Microwave oven

Store antitheft gate

Airport security gate

Proximity to cell-phone relay

Microcell (small relay antenna)

Proximity to radio. TV transmitter

MRI, scanner

9

Other $^{\ddagger}$

5

Low and high frequency devices

Other $^{\S}$

7

X-ray devices

Radiographic equipment

6

2.8 


\section{Unknown frequency}

Other" 3

Remote control 1

Do not know $\quad 29$

\section{Percentages calculated only for $n \geq 5$}

* Physicians were not always able to identify a single device; some suspected 2 or more sources for a single incident - whence the number of sources exceeding the number of incidents.

'Physicians were not always able to distinguish radiofrequency and other frequency-range transmitters; sources were grouped together, without excluding non-radiofrequency sources, as the information seemed useful.

Other low-frequency devices: electrotherapy (2), electric train, power lines (2), electrified fence (2), hairdresser's gown button magnet, defective household equipment (2), car battery recharge, loud-speaker (3), electric transformer, weapons detector.

${ }^{\ddagger}$ Other high frequency devices: ski entry gate (2), surgical sterilizer (1), in-car IT equipment (2).

${ }^{\S}$ Other high- and low-frequency devices: welding iron, arc welder (3), induction hotplate.

"Other devices of unknown frequency: working environment, electrical equipment, electrical DIY equipment. 
Figure 1: Breakdown of study population

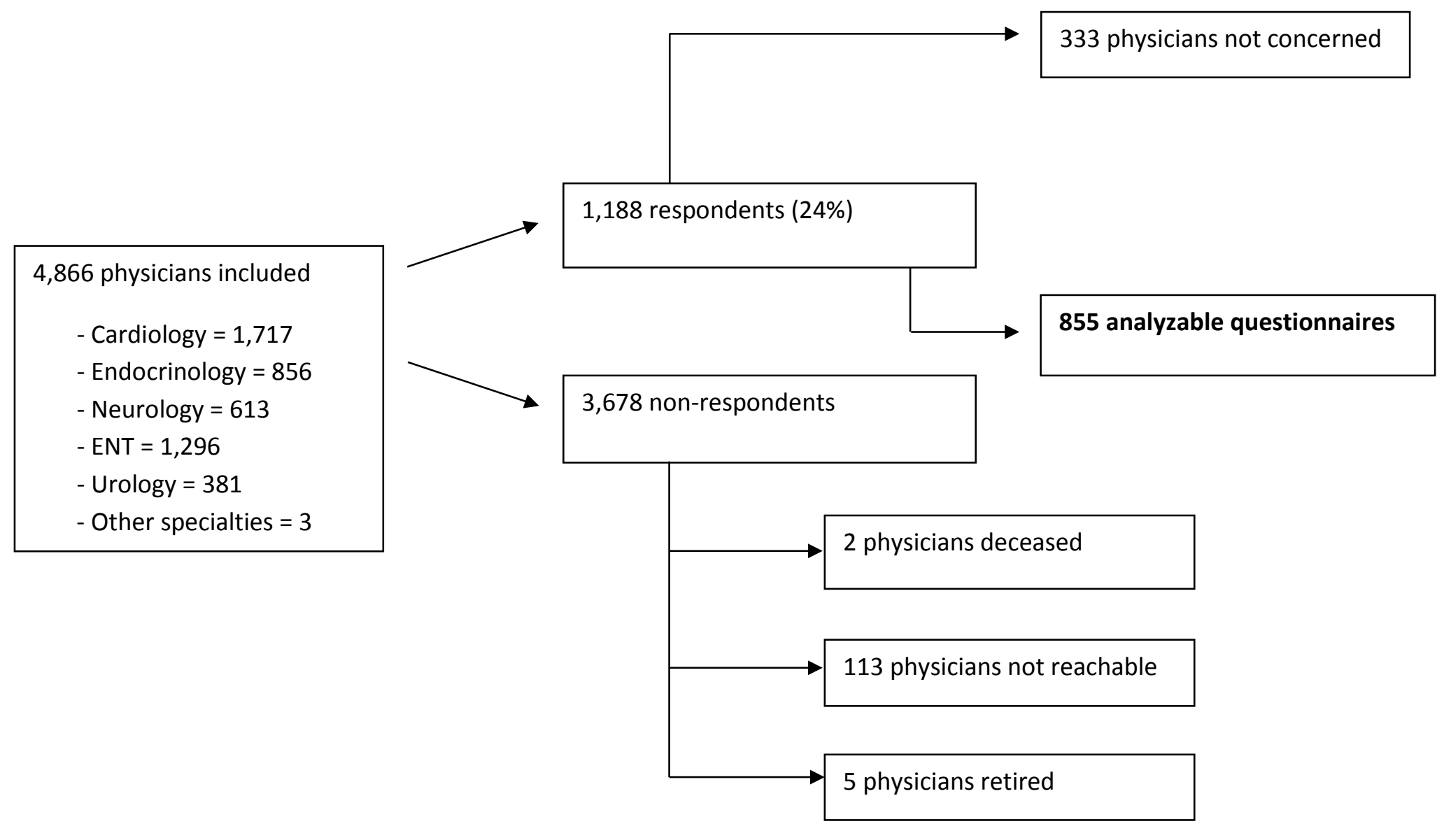

